\title{
PERAN KEPERCAYAAN PADA PENGAWAS MEMEDIASI PENGARUH PEMBERDAYAN KARYAWAN TERHADAP PERILAKU KERJA INOVATIF
}

\author{
Ni Nyoman Surya Cahyani 1 \\ Ayu Desi Indrawati ${ }^{2}$ \\ ${ }^{1,2}$ Fakultas Ekonomi dan Bisnis Universitas Udayana (Unud), Bali, Indonesia \\ e-mail: suryacahyani_mj11@yahoo.com
}

\begin{abstract}
ABSTRAK
Perilaku kerja inovatif merupakan perilaku yang meliputi eksplorasi peluang ide-ide baru, mencakup menerapkan pengetahuan baru dan upaya peningkatan kinerja pribadi atau bisnis pada perusahaan. Tujuan penelitian ini untuk mengetahui pengaruh pemberdayan karyawan terhadap kepercayaan pada pengawas dan perilaku kerja inovatif. Penelitian ini dilakukan di Bale Udang Mang Engking Ubud dengan populasi seluruh karyawan perusahaan. Jumlah sampel yang diambil sebanyak 74 sampel dengan menggunakan metode sampling jenuh. Metode pengumpulan data dilakukan melalui wawancara dan penyebaran kuisioner. Teknik analisis yang digunakan adalah analisis jalur (path analysis). Penelitian ini menggunakan uji sobel untuk mendeteksi variabel mediasi. Hasil penelitian menunjukkan bahwa pemberdayaan karyawan berpengaruh positif dan signifikan terhadap kepercayaan pada pengawas. Pemberdayaan karyawan berpengaruh positif dan signifikan terhadap perilaku kerja inovatif, kepercayaan pada pengawas berpengaruh positif dan signifikan terhadap perilaku kerja inovatif, selanjutnya kepercayaan pada pengawas memiliki peran memediasi pengaruh pemberdayaan karyawan terhadap perilaku kerja inovatif bagi karyawan.
\end{abstract}

Kata kunci: perilaku kerja inovatif, pemberdayan karyawan, kepercayaan pengawas

\begin{abstract}
Innovative work behaviors are behaviors that include exploration new idea, applying new knowledge and achieving business performance improvements to the company. The purpose of study was determine the effect of employee empowerment on trust in supervisor and innovative work behaviour. The population is all of the employees in Bale Udang Mang Engking Ubud, with number of sample were 74 samples. The data collection method is conducted by interviews and questionnaires. The path analysis and the sobel test were used to detect the mediating variable. The result shows that employee empowerment has positive and significant influence on trust in supervisor. Employee Empowerment has positive and significant influence on trust in supervisor. Trust in supervisor has positive and significant influence on innovative work behaviour. Trust in supervisor is accepted as an intervening variable in mediating the employee empowerment on innovative work behaviour.
\end{abstract}

Keywords: innovative work behaviour, employee empowerment, trust in supervisor 


\section{PENDAHULUAN}

Keberhasilan pengelolaan perusahaan sangat ditentukan oleh kegiatan pendayagunaan sumber daya manusia, dimana manajer perusahaan harus benarbenar memperhatikan sikap, perilaku, keinginan dan kebutuhan dari karyawan sehingga karyawan tersebut didorong untuk meningkatkan kinerjanya (Suryadewi dkk., 2014). Karyawan pada masa kini diharapkan dapat mengembangkan potensi dirinya melalui daya imajinasi, kecerdikan, inisiatif serta kreativitas yang sangat bermanfaat demi kemajuan perusahaan. Bila dalam perusahaan tidak ada suatu keinovatifan dalam bekerja, maka produktivitas perusahaan tertinggal dari perusahaan pesaingnya.

Perilaku kerja inovatif merupakan proses implementasi ide-ide baru yang mampu meningkatkan kreativitas karyawan dalam menghadapi persaingan perusahaan sehingga perlu didorong dengan adanya pemberdayaan karyawan. De Jong \& Hartog (2010) menyatakan perilaku kerja inovatif tidak hanya sekedar menghasilkan ide baru tetapi juga melibatkan proses implementasi ide khususnya pada setting pekerjaan.

Pemberdayaan adalah hal penting mendorong orang untuk lebih terlibat dalam pembuatan keputusan di suatu perusahaan (Wibowo, 2012:416).Dalam pengimplementasian pemberdayaan karyawan perlunya suatu kepercayaan dari karyawan pada atasan atau pengawasnya karena akan berpengaruh pada keyakinan mereka untuk melaksanakan setiap tugas-tugas. Mahdi (2008:160) dalam Ratnawati (2013) menyatakan, kepercayaan terhadap pengawas atau atasan 
merupakan sikap tidak ragu-ragu dari seseorang karyawan kepada atasannya atau pengawas atas kebijakan yang dilakukan atasan tersebut.

Moye \& Henkin (2006) menyatakan bahwa adanya pemberdayaan karyawan maka karyawan memiliki kepercayaan tinggi pada atasannya dalam perusahaan manufaktur Amerika Serikat.Byaruhanga dan Othuma (2014) menyatakan bahwa pemberdayaan karyawan dapat menciptakan kepercayaan pada manajernya oleh para karyawan di rumah sakit.

Riset yang dihasilkan oleh Ertürk (2012) bahwa pemberdayaan dapat mengarah pada perilaku kerja inovatif pada sektor industrial. Çakar and Ertürk (2010), Ertürk (2012), Khodabakhshi et al. (2013) menyatakan bahwa pemberdayaan berpengaruh signifikan pada perilaku kerja inovatif. Hal ini diperkuat oleh Alkhodary (2016) bahwa adanya pemberdayaan karyawan maka tercipta perilaku kerja inovatif pada karyawan perusahaan desain interior di Yordania.

Pemberdayaan karyawan sebagai penentu kepercayaan karyawan pada atasannya mampu meningkatkan perilaku kerja inovatif. Kepercayaan menjadi variabel perantara yang menjelaskan hubungan tidak langsung antara pemberdayaan dan perilaku kerja inovatif.Ertürk (2012) menyatakan bahwa peran kepercayaan pada pengawas dalam memediasi pemberdayaan karyawan berpengaruh positif dan signifikan terhadap perilaku kerja inovatif seluruh karyawan perusahaan manufaktur di Istanbul.

Bale Udang Mang Engking Ubud adalah Restoran Indonesia dengan ciri khas Sunda dan Bali yang menghadirkan pengalaman bersantap yang menarik di 
bale sambil menikmati hidangan yang segar dan lezat. Restoran ini menyediakan makanan berkualitas tinggi untuk para konsumennya dan para karyawan siap melayani dengan tulus, karena kepuasan pelanggan adalah tujuan utama dari restoran ini. Memiliki 74 karyawan dengan staf-staf bagian meliputi Operational Manager, staf bagian $F \& B$ productions (bar dan kirchen), staf bagian $F \& B$ services (pelayan dan kasir), sales \& marketing, administrasi \& general, housekeeping\& gardener, engineeringdan security. Restoran ini memberikan kesempatan yang sangat terbuka lebar untuk karyawannya dalam menyampaikan ide-ide baru yang kreatif dan inovatif dalam pengembangan skill karyawan dan kemajuan perusahaan itu sendiri.

Adapun permasalahan pemberdayaan karyawan yang terjadi di restoran ini meliputi adanya beberapa karyawan beridealisme yang tidak sesuai dengan prosedur perusahaan, adanya ketidaksesuaian job desc dengan skill karyawan, dan kurangnya minat karyawan untuk saling berkompetisi, serta kecemburuan karyawan saat pembagian waktu cuti hari raya dari atasan atau pengawas. Masalah perilaku kerja inovatifmeliputi adanya beberapa karyawan yang tidak mempedulikan suatu perubahan dan kurang adanya inisiatif serta karyawan masih bergantung dari komando pengawas (atasan).

Berdasarkan latar belakang permasalahan di atas, maka rumusan masalah dari penelitian ini adalah 1). Bagaimana pengaruh Pemberdayaan Karyawan terhadap Kepercayaan pada Pengawas ? 2). Bagaimana pengaruh Pemberdayaan Karyawan terhadap Perilaku Kerja Inovatif ? 3). Bagaimana pengaruh Kepercayaan pada Pengawas terhadap Perilaku Kerja Inovatif ? 
Ni Nyoman Surya Cahyani, Peran Kepercayaan pada Pengawas...

4).Bagaimana peran Kepercayaan pada Pengawas dalam memediasi pengaruh Pemberdayaan Karyawan terhadap Perilaku Kerja Inovatif ?

Penelitian ini diharapkan dapat memperkaya bidang ilmu manajemen sumber daya manusia secara empirik, khususnya dalam aspek perilaku kerja inovatif, pemberdayaan karyawan dan kepercayaan pada pengawassehingga dapat memperbaiki kelemahan-kelemahan yang terjadi di dalam perusahaan. Manfaat Praktis dari hasil penelitian ini diharapkan sebagai bahan pertimbangan dan masukan terhadap pihak atau manajemen Bale Udang Mang Engking Ubud, yang dapat membantu perusahaan dalam mencapai tujuan organisasi.

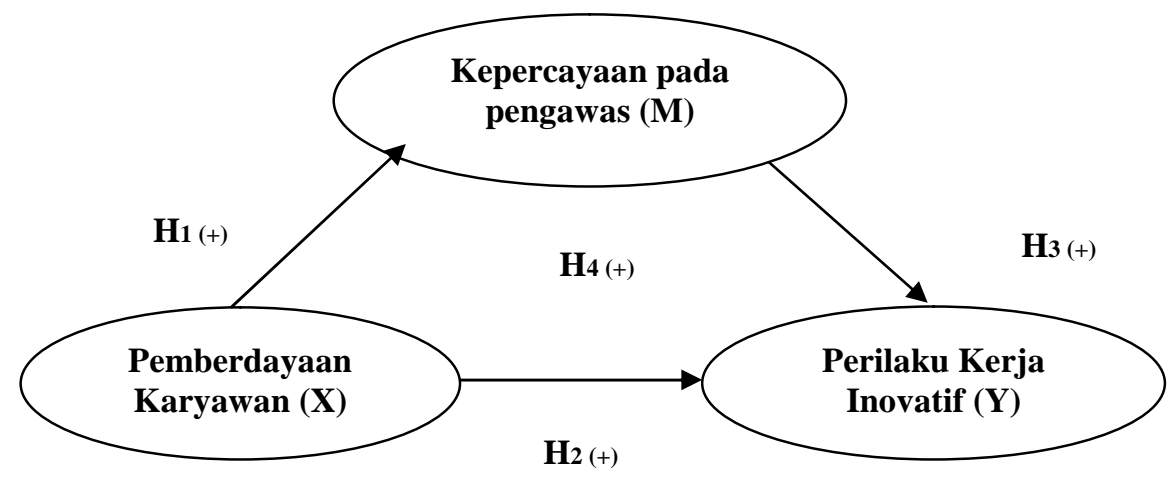

Gambar 1. Desain Penelitian

Moye \& Henkin (2006) menyatakan bahwa karyawan yang diberdayakan pada lingkungan kerjanya, maka memiliki kepercayaan tinggi pada atasan atau pengawas mereka di sebuah perusahaan manufaktur Amerika Serikat. Studi empiris yang dilakukan oleh Shelton (2002) menyatakan bahwa pemberdayaan karyawan yang tinggi akan menimbulkan kepercayaan kepada pengawas yang tinggi pada perusahaan sektor publik. Berdasarkan ulasan studi empiris di atas, maka dapat dikembangkan hipotesis sebagai berikut: 
$\mathrm{H}_{1}$ : Pemberdayaan karyawan berpengaruh positif signifikan terhadap kepercayaan pada pengawas.

Ertürk (2012) menyatakan bahwa pemberdayaan dapat mengarah pada perilaku kerja inovatif pada sektor industrial. Çakar \& Ertürk (2010), Ertürk (2012), Khodabakhshi et al. (2013) menyatakan bahwa pemberdayaan berpengaruh signifikan pada perilaku kerja inovatif. Berdasarkan ulasan studi empiris di atas, maka dapat dikembangkan hipotesis sebagai berikut:

$\mathrm{H}_{2}$ : Pemberdayaan karyawan berpengaruh positif signifikan terhadap perilaku kerja inovatif.

Saswitaningrum (2013) mengemukakan bahwa kepercayaan pada atasan atau pengawas berpengaruh positif terhadap perilaku kerja inovatif guru di SMK 2 Sewon-Bantul. Lee (2008) menyatakan bahwa kepercayaan pada atasan dapat mempengaruhi secara signifikan perilaku kerja inovatif pegawai sektor publik di Korea Selatan. Seo et al. (2016) menemukan bahwa adanya kepercayaan pada atasan atau pengawas berpengaruh signifikan pada para pelatih klub fitnes. Berdasarkan ulasan studi empiris di atas, maka dapat dikembangkan hipotesis sebagai berikut:

$\mathrm{H}_{3}$ : Kepercayaan pada pengawas berpengaruh positif signifikan terhadap perilaku kerja inovatif

Brunetto \& Wharton (2007) mengemukakan bahwa pemberdayaan karyawan memiliki dampak positif pada kepercayaan pada atasan.Hasil penelitian Berraies (2014) menemukan peran mediasi kepercayaan pada atasan atau pengawas mempengaruhi hubungan pemberdayaan karyawan terhadap perilaku kerja inovatif yang eksploitatif pada karyawan perusahaan ICT di 
Tunisia.Berdasarkan ulasan studi empiris di atas, maka dapat dikembangkan hipotesis sebagai berikut:

$\mathrm{H}_{4}$ : Kepercayaan pada pengawas memediasi pengaruh pemberdayaan karyawan terhadap perilaku kerja inovatif.

\section{METODE PENELITIAN}

Penelitian ini menggunakan pendekatan kuantitatif yang bersifat asosiatif yaitu terdapat hubungan kausal (sebab-akibat) antara variabel eksogen (X) yaitu pemberdayaan karyawan dengan variabel endogenyaitu $(\mathrm{Y})$ perilaku kerja inovatif dan variabel mediasi (M) kepercayaan pada pengawas. Lokasi penelitian ini bertempat di Bale Udang Mang Engking Ubud di Jalan Goa Gajah, Peliatan Ubud.Objek penelitian ini meliputi; (1) Perilaku Kerja Inovatif, (2) Pemberdayaan Karyawan, dan (3) Kepercayaan pada Pengawas di Bale Udang Mang Engking Ubud.

Populasi penelitian ini adalah seluruh karyawan Bale Udang Mang Engking Ubud yang berjumlah 74 orang karyawan.Penentuan sampel pada penelitian ini adalah metode sampling jenuh dengan sampel dalam penelitian ini berjumlah 74 orang darirestoran. Penelitian ini dilakukan dengan menggunakan metode pengumpulan data berupa wawancara dan kuesioner.

Uji validitas bertujuan untuk memeriksa apakah kuesioner sebagai instrumen penelitian sudah tepat untuk mengukur apa yang seharusnya diukur (Sugiyono, 2014:172).Uji reliabilitas bertujuan untuk mencari tahu sampai sejauh mana konsistensi alat ukur yang digunakan.Suatu kuesioner dikatakan reliabel 
atau handal jika jawaban seseorang terhadap pernyataan adalah konsisten atau stabil dari waktu ke waktu (Sugiyono, 2014:180).

Teknik analisis data yang digunakan meliputi Uji Asumsi Klasik dan Analisis Jalur (path analysis). Uji asumsi klasik meliputiuji normalitas, uji multikolinieritas dan uji heteroskedasitas. Uji normalitas dilakukan untuk menguji apakah dalam sebuah model regresi, residu dari persamaan regresi mempunyai distribusi normal atau tidak.Ghozali (2006:91) menyatakan Uji Multikolinearitas bertujuan untuk menguji dalam model regresi ditemukan adanya korelasi antar variabel-variabel bebas. Uji heterokedastisitas dilakukan untuk mengetahui bahwa pada model regresi terjadi ketidaksamaan varian, mendeteksi ada atau tidaknya heterokedastisitas digunakan model glejser.

Model analisis Analisis Jalur (Path Analysis) dengan bantuan Program Komputer SPSS (Statistical Package for Social Science) versi 16.00. Model Analisis Jalur (Path Analysis) dilakukan dengan menggunakan korelasi, regresi dan jalur, sehingga dapat diketahui untuk sampai pada varibel endogen terakhir harus melewati jalur langsung, atau melalui variable intervening (Sugiyono, 2014: 70).

\section{HASIL DAN PEMBAHASAN}

\section{Karakteristik Responden}

Data karakteristik responden bertujuan untuk mengetahui profil responden penelitian, meliputi empat aspek yaitu; jenis kelamin, usia, pendidikan terakhir dan masa kerja. 
Berdasarkan jenis kelamin dapat dilihat secara rinci dengan penjelasan sebagai berikut:

Tabel 1.

Karakteristik RespondenBerdasarkan Jenis Kelamin

\begin{tabular}{llc}
\hline \multicolumn{1}{c}{ Jenis Kelamin } & \multicolumn{2}{c}{ Jumlah } \\
& N & Persentase (\%) \\
\hline Laki-Laki & 40 & 54,05 \\
Perempuan & 34 & 45,95 \\
Jumlah & $\mathbf{7 4}$ & $\mathbf{1 0 0 , 0 0}$ \\
\hline
\end{tabular}

Sumber: Data Primer Diolah, 2018

Tabel 1 menyatakan bahwa, karyawan di Bale Udang Mang Engking Ubud didominasi oleh karyawan berjenis kelamin laki-laki yang berjumlah 40 orang dengan persentase 54,05 persen.Jadi dapat disimpulkan bahwa karyawan di Bale Udang Mang Engking Ubud lebih banyak memiliki karyawan laki-laki daripada karyawan perempuan.

Responden berdasarkan usia dapat dilihat secara rinci dengan penjelasan sebagai berikut:

Tabel 2.

Karakteristik RespondenBerdasarkan Usia

\begin{tabular}{lrc}
\hline \multicolumn{1}{c}{ Usia } & \multicolumn{2}{c}{$\begin{array}{c}\text { Jumlah } \\
\text { Persentase (\%) }\end{array}$} \\
\hline $16-27$ tahun & 42 & 56,76 \\
$28-40$ tahun & 27 & 36,49 \\
$40-60$ tahun & 5 & 6,75 \\
\hline Jumlah & $\mathbf{7 4}$ & $\mathbf{1 0 0 , 0 0}$ \\
\hline Sumber: Data Primer Diolah, 2018 &
\end{tabular}

Tabel 2 menunjukkan bahwa karyawan Bale Udang Mang Engking Ubud rata-rata berusia 16 - 27 tahun, sebanyak 42 orang dengan persentase 56,76 persen. Jumlah ini sesuai dengan yang dibutuhkan oleh perusahaan, yaitumencari karyawan yang lebih cepat tanggap, responsif dan memiliki fisik lebih prima 
untuk jenis pekerjaan yang membutuhkan power lebihbesar yang didominasi oleh kalangan muda.

Responden berdasarkan pendidikan terakhir dapat dilihat secara rinci dengan penjelasan sebagai berikut :

Tabel 3.

Karakteristik RespondenBerdasarkan Pendidikan

\begin{tabular}{lrc}
\hline \multicolumn{1}{c}{ Pendidikan Terakhir } & N & $\begin{array}{c}\text { Jumlah } \\
\text { Persentase (\%) }\end{array}$ \\
\hline SMA/SMK & 56 & 75,68 \\
Diploma & 13 & 17,56 \\
Sarjana & 5 & 6,76 \\
Jumlah & $\mathbf{7 4}$ & $\mathbf{1 0 0 , 0 0}$ \\
\hline Sumber: Data Primer Diolah, 2018 &
\end{tabular}

Tabel 3 menunjukkan jumlah tertinggi terletak pada tingkat pendidikan terakhir SMA/SMK/Sederajat sebanyak 56 orang dengan persentase 75,68 persen. Faktor tingkat pendidikan merupakan salah satu penentu kualitas SDM.

Responden berdasarkan masa kerja dapat dilihat secara rinci dengan penjelasan sebagai berikut :

Tabel 4.

Karakteristik RespondenBerdasarkan Masa Kerja

\begin{tabular}{lcc}
\hline \multicolumn{1}{c}{ Masa Kerja } & N & $\begin{array}{c}\text { Jumlah } \\
\text { Persentase (\%) }\end{array}$ \\
\hline$>1,5$ tahun & 13 & 17,57 \\
$1,5-3$ tahun & 20 & 27,03 \\
$3-4$ tahun & 41 & 55,40 \\
Jumlah & $\mathbf{7 4}$ & $\mathbf{1 0 0 , 0 0}$ \\
\hline Sumber: Data Primer Diolah, 2018 &
\end{tabular}

Tabel 4 menunjukkan bahwa tingginya loyalitas karyawan terhadap restoran mencapai 55,40 persen dengan jumlah 41 orang karyawan bekerja selama 3 - 4 tahun lamanya. Tingginya kesetiaan karyawan ini mampu menjaga rasa keamanan, kenyamanaan, dan kekeluargaan antar karyawan serta loyalitas terhadap perusahaan. Bagi karyawan yang masa kerjanya masih dibawah 1,5 
tahun dengan jumlah 13 orang atau mencapai 17,57 persen, merupakan karyawan yang baru bergabung dengan Bale Udang Mang Engking Ubud.

\section{Hasil Pengujian Instrumen Penelitian}

\section{Uji Validitas}

Tabel 5.

Hasil Uji Validitas

\begin{tabular}{cccccc}
\hline No & Variabel & $\begin{array}{c}\text { Item } \\
\text { Pernyataan }\end{array}$ & $\begin{array}{c}\text { Korelasi } \\
\text { Item Total }\end{array}$ & Sig & Keterangan \\
\hline 1 & Pemberdayaan & $\mathrm{X}_{1}$ & 0,888 & 0,000 & Valid \\
& Karyawan & $\mathrm{X}_{2 .}$ & 0,917 & 0,000 & Valid \\
& $(\mathrm{X})$ & $\mathrm{X}_{3 .}$ & 0,900 & 0,000 & Valid \\
& & $\mathrm{X}_{4}$ & 0,864 & 0,000 & Valid \\
& Perilaku Kerja & $\mathrm{Y}_{1}$ & 0,824 & 0,000 & Valid \\
& Inovatif & $\mathrm{Y}_{2 .}$ & 0,867 & 0,000 & Valid \\
& (Y) & $\mathrm{Y}_{3 .}$ & 0,889 & 0,000 & Valid \\
& Kepercayaan & $\mathrm{Y}_{4}$ & 0,841 & 0,000 & Valid \\
& pada Pengawas & $\mathrm{M}_{1}$ & 0,890 & 0,000 & Valid \\
& (M) & $\mathrm{M}_{2 .}$ & 0,852 & 0,000 & Valid \\
& & $\mathrm{M}_{3 .}$ & 0,904 & 0,000 & Valid \\
& $\mathrm{M}_{4}$ & 0,866 & 0,000 & Valid \\
& & $\mathrm{M}_{5}$ & 0,850 & 0,000 & Valid \\
\hline
\end{tabular}

Sumber: data diolah, 2018

Berdasarkan Tabel 5, dapat diketahui bahwa seluruh koefisien korelasi dari indikator variabel penelitian yang diuji nilainya lebih besar dari $0,30(\mathrm{r}>0,3)$ dan Sig $<0,05$. hasil tersebut menunjukkan bahwa seluruh indikator penelitian dinyatakan valid.

Tabel 6.

\section{Hasil Uji Reliabilitas}

\begin{tabular}{llll}
\hline No & Variabel & Cronbach's Alpha & Keterangan \\
\hline 1 & Pemberdayaan Karyawan (X) & 0,913 & Reliabel \\
2 & Perilaku Kerja Inovatif (Y) & 0,877 & Reliabel \\
3 & Kepercayaan pada Pengawas (M) & 0,919 & Reliabel \\
\hline \multicolumn{2}{l}{ Sumber: data diolah, 2018 }
\end{tabular}

Berdasarkan Tabel 6, dapat diperoleh bahwa masing-masing nilai Cronbach's Alpha pada tiap instrumen penelitian lebih besar dari 0,6 (Cronbach's 
Alpha $>0,6)$. Hasil tersebut menunjukkan bahwa semua instrumen dinyatakan reliabel, sehingga dapat digunakan untuk melakukan penelitian.

\section{Deskripsi Variabel Penelitian}

\section{Tabel 7.}

Frekuensi Jawaban Responden terhadap Pemberdayaan Karyawan

\begin{tabular}{|c|c|c|c|c|c|c|c|}
\hline \multirow{2}{*}{ Indikator } & \multicolumn{5}{|c|}{ Skor Jawaban } & \multirow{2}{*}{$\begin{array}{l}\text { Jumlah } \\
\text { Skor }\end{array}$} & \multirow[t]{2}{*}{ Rata-Rata } \\
\hline & 1 & 2 & 3 & 4 & 5 & & \\
\hline $\begin{array}{l}\text { Hubungannya pada idealisme atau } \\
\text { standar individu. }\left(\mathrm{X}_{.1}\right)\end{array}$ & 0 & 1 & 10 & 50 & 13 & 297 & 4,01 \\
\hline $\begin{array}{l}\text { Kepercayaan individu akan kemampuan } \\
\text { mereka dalam melakukan aktivitas }\left(\mathrm{X}_{.2}\right)\end{array}$ & 0 & 0 & 15 & 42 & 17 & 298 & 4,02 \\
\hline $\begin{array}{l}\text { Perasaan memiliki suatu pilihan dalam } \\
\text { membuat pilihan pekerjaan }\left(\mathrm{X}_{.3}\right)\end{array}$ & 0 & 3 & 19 & 37 & 15 & 286 & 3,86 \\
\hline $\begin{array}{l}\text { Derajat seseorang dapat mempengaruhi } \\
\text { hasil pekerjaan baik strategik, } \\
\text { administratif, maupun operasional (X.4) }\end{array}$ & 0 & 1 & 15 & 38 & 20 & 299 & 4,04 \\
\hline \multicolumn{7}{|c|}{ Rata-Rata } & 3,98 \\
\hline
\end{tabular}

Sumber: data diolah, 2018

Berdasarkan Tabel 7, dapat diketahui jawaban responden terhadap pemberdayaan karyawan pada Bale Udang Mang Engking Ubudmemiliki nilai rata-rata sebesar 3,98. Adapun nilai rata-rata tersebut berada pada interval 3,41 s/d 4,20 yang tergolong tinggi.

Tabel 8.

Frekuensi Jawaban Responden terhadap Kepercayaan padaPengawas

\begin{tabular}{|c|c|c|c|c|c|c|c|}
\hline \multirow{2}{*}{ Indikator } & \multicolumn{5}{|c|}{ Skor Jawaban } & \multirow{2}{*}{$\begin{array}{l}\text { Jumlah } \\
\text { Skor }\end{array}$} & \multirow[t]{2}{*}{ Rata-Rata } \\
\hline & 1 & 2 & 3 & 4 & 5 & & \\
\hline Kemampuan pengawas melalui & & & & & & & \\
\hline $\begin{array}{l}\text { kepemimpinannya dan kapabilitas dalam } \\
\text { menghadapi tantangan }\left(\mathrm{M}_{1}\right)\end{array}$ & 1 & 2 & 12 & 44 & 15 & 292 & 3,95 \\
\hline $\begin{array}{l}\text { Komunikasi pengawas dalam } \\
\text { menghadapi masalah-masalah dan } \\
\text { keputusan-keputusa kepada para } \\
\text { karyawannya }\left(\mathrm{M}_{2}\right)\end{array}$ & 0 & 0 & 18 & 39 & 17 & 295 & 3,99 \\
\hline $\begin{array}{l}\text { Kepedulian pengawas terhadap para } \\
\text { karyawannya }\left(\mathrm{M}_{3}\right)\end{array}$ & 0 & 2 & 15 & 41 & 16 & 293 & 3,96 \\
\hline $\begin{array}{l}\text { Kemantapan pengawas dalam } \\
\text { membangun kepercayaan terhadap } \\
\text { karyawannya }\left(\mathrm{M}_{4}\right)\end{array}$ & 0 & 1 & 15 & 43 & 15 & 294 & 3,97 \\
\hline $\begin{array}{l}\text { Koneksi atau hubungan antara pengawas } \\
\text { dan karyawan }\left(\mathrm{M}_{5}\right)\end{array}$ & 0 & 0 & 11 & 44 & 19 & 304 & 4,11 \\
\hline & ta-F & & & & & & 3,99 \\
\hline
\end{tabular}

Sumber: data diolah, 2018 
Ni Nyoman Surya Cahyani, Peran Kepercayaan pada Pengawas...

Berdasarkan Tabel 8, dapat diketahui jawaban responden terhadap kepercayaan pada pengawas memiliki nilai rata-rata sebesar 3,99. Adapun nilai rata-rata tersebut berada pada interval 3,41 s/d 4,20 yang tergolong tinggi.

Tabel 9.

Frekuensi Jawaban Responden terhadap Perilaku Kerja Inovatif

\begin{tabular}{|c|c|c|c|c|c|c|c|}
\hline \multirow{2}{*}{ Indikator } & \multicolumn{5}{|c|}{ Skor Jawaban } & \multirow{2}{*}{$\begin{array}{l}\text { Jumlah } \\
\text { Skor }\end{array}$} & \multirow[t]{2}{*}{ Rata-Rata } \\
\hline & 1 & 2 & 3 & 4 & 5 & & \\
\hline $\begin{array}{l}\text { Menemukan kesempatan atau sebuah } \\
\text { masalah }\left(\mathrm{Y}_{1}\right)\end{array}$ & 0 & 2 & 19 & 45 & 8 & 281 & 3,80 \\
\hline Menciptakan dan menyarankan ide $\left(\mathrm{Y}_{2}\right)$ & 0 & 0 & 12 & 37 & 25 & 309 & 4,18 \\
\hline $\begin{array}{l}\text { Mencari dukungan dalam mewujudkan } \\
\text { ide inovasi baru }\left(\mathrm{Y}_{3}\right)\end{array}$ & 0 & 1 & 15 & 40 & 18 & 297 & 4,01 \\
\hline $\begin{array}{l}\text { Keberanian untuk menerapkan ide } \\
\text { baru }\left(\mathrm{Y}_{4}\right)\end{array}$ & 0 & 0 & 13 & 45 & 16 & 299 & 4,04 \\
\hline Rata- & & & & & & & 4,01 \\
\hline
\end{tabular}

Sumber: data diolah, 2018

Berdasarkan Tabel 9, dapat diketahui jawaban responden terhadap perilaku kerja inovatif pada Bale Udang Mang Engking Ubudmemiliki nilai rata-rata sebesar 4,01. Adapun nilai rata-rata tersebut berada pada interval $3,41 \mathrm{~s} / \mathrm{d} 4,20$ yang tergolong tinggi.

\section{Hasil Asumsi Klasik}

Adapun pengujian asumsi klasik dalam penelitian ini meliputi, uji normalitas, uji multikolinearitas dan uji heteroskedastisitas. Berdasarkan penghitungan melalui SPSS pada tabel 10, nilai signifikansi yang diperoleh sebesar 0,77 dimana nilai signifikan $0,77>0,05$. Hasil ini menunjukkan bahwa model regresi I penelitian ini terdistribusi normal. 
Tabel 10.

Hasil Uji Normalitas Model I

One-Sample Kolmogorov-Smirnov Test

\begin{tabular}{|c|c|c|c|}
\hline & & & $\begin{array}{l}\text { Unstandardiz } \\
\text { ed Residual }\end{array}$ \\
\hline \multicolumn{3}{|l|}{$\mathrm{N}$} & 74 \\
\hline \multirow[t]{2}{*}{ Normal Parameters } & $a, b$ & Mean & .0000000 \\
\hline & & Std. Deviation & 1.07596214 \\
\hline Most Extreme & & Absolute & .148 \\
\hline \multirow[t]{2}{*}{ Differences } & & Positive & .118 \\
\hline & & Negative & -.148 \\
\hline \multicolumn{3}{|c|}{ Kolmogorov-Smirnov Z } & 1.275 \\
\hline \multicolumn{3}{|c|}{ Asymp. Sig. (2-tailed) } & .077 \\
\hline
\end{tabular}

a. Test distribution is Normal.

b. Calculated from data.

Sumber: data diolah, 2018

Tabel 11.

Hasil Uji Normalitas Model II One-Sample Kolmogorov-Smirnov Test

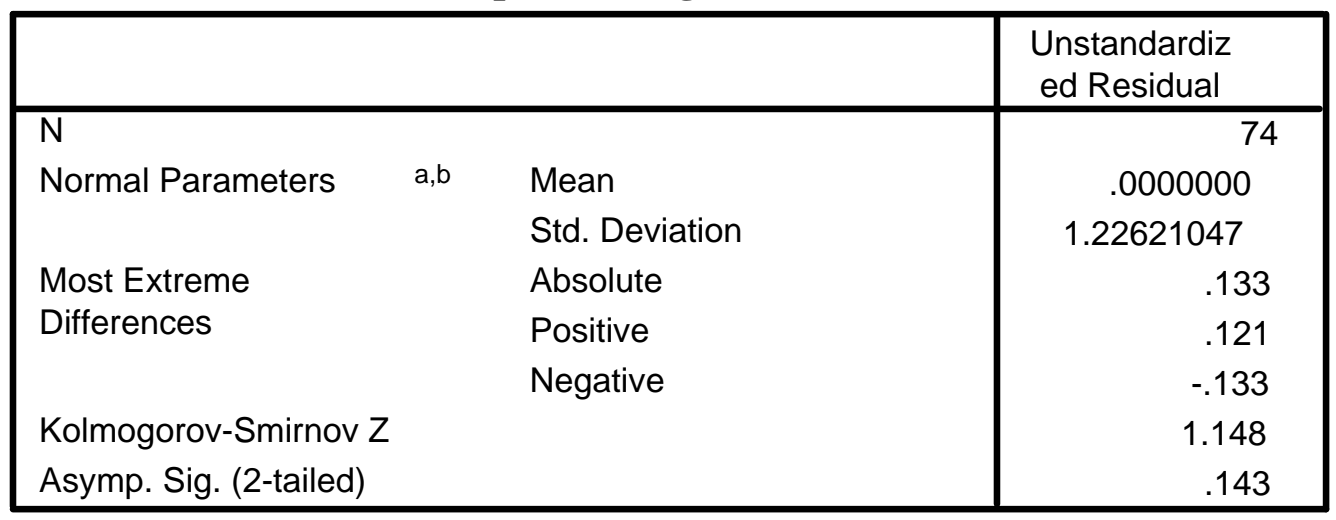

a. Test distribution is Normal.

b. Calculated from data.

Sumber : data diolah, 2018

Berdasarkan penghitungan melalui SPSS pada tabel 11 nilai signifikansi yang diperoleh sebesar 0,143 dimana nilai signifikan 0,143>0,05.

Tabel 12.

Hasil Uji Multikolinearitas Model I

\begin{tabular}{lcr}
\hline \multicolumn{1}{c}{ Variabel } & Nilai Tolerance & Nilai VIF \\
\hline Pemberdayaan Karyawan $(\mathrm{X})$ & 1,000 & 1,000 \\
\hline Sumber: data diolah, 2018 & &
\end{tabular}


Tabel 12 menyatakan bahwa nilai tolerance pada variabel bebas $>0,10$ dan nilai $\mathrm{VIF}<10$, maka disimpulkan bahwa model penelitian tersebut tidak terdapat gejala multikolinearitas.

Tabel 13.

Hasil Uji Multikolinearitas Model II

\begin{tabular}{lcc}
\hline \multicolumn{1}{c}{ Variabel } & Nilai Tolerance & Nilai VIF \\
\hline Pemberdayaan Karyawan (X) & 0,125 & 7,998 \\
& 0,125 & 7,998 \\
\hline Kepercayaan pada Pengawas (M) & &
\end{tabular}
Sumber: data diolah, 2018

Tabel 13 menyatakan bahwa nilai tolerance pada setiap variabel bebas > 0,10 dan nilai VIF <10, maka disimpulkan bahwa model penelitian tersebut tidak terdapat gejala multikolinearitas.

Tabel 14.

Hasil Uji Heteroskedastisitas Model I

\begin{tabular}{lcc}
\hline \multicolumn{1}{c}{ Variabel } & Signifikansi & Keterangan \\
\hline Pemberdayaan karyawan $(\mathrm{X})$ & 0,665 & Bebas Heteroskedastisitas \\
\hline Sumber: data diolah, 2018 & &
\end{tabular}

Tabel 15. Hasil Uji Heteroskedastisitas Model II

\begin{tabular}{lcc}
\hline \multicolumn{1}{c}{ Variabel } & Signifikansi & Keterangan \\
\hline Pemberdayaan karyawan $(\mathrm{X})$ & 0,091 & Bebas Heteroskedastisitas \\
Kepercayaan pada Pengawas (M) & 0,146 & Bebas Heteroskedastisitas
\end{tabular}

Sumber: data diolah, 2018

Berdasarkan uji glejser pada Tabel 14 dan Tabel 15 dapat disimpulkan, nilai signifikansi dari masing-masing variabel lebih besar atau diatas 0,05 hal ini menyatakan bahwa seluruh variabel terbebas dari masalah heteroskedastisitas.

\section{Hasil Analisis Jalur (Path Analysis)}

Penelitian ini menggunakan teknik analisis jalur (Path Analysis) untuk menguji data, seperti yang diketahui analisis jalur adalah perluasan dari analisis 
regresi linear berganda.Laporan hasil analisis jalur persamaanregresi model I setelah diolah dapat dibentuk persamaan substruktur 1 sebagai berikut:

Persamaan substruktur 1:

$\mathbf{M}=\mathbf{a X}+\mathbf{e} 1$

$\mathrm{M} \quad=0,935 \mathrm{X}$

$\mathrm{S}(ß) \quad=(0,935)$

$\mathrm{t} \quad=(22,447)$

Sig $=(0,000)$

$\mathrm{R}^{2}=(0,875) \mathrm{df}_{1}=1 \quad \mathrm{df}_{2}=72 \mathrm{~F}=503,874 \mathrm{Sig}=0,000$

Hasil perhitungan F sebesar 503.874 dengan nilai signifikansi sebesar 0,000, yang berarti lebih kecil darialpha 0,05 . Hasil ini memberikan kesimpulan bahwa regresi model I yaitu variabel pemberdayaan karyawan(X) berpengaruh siginifikan pada variabel kepercayaan pada pengawas $(\mathrm{M})$. Besarnya nilai $\mathrm{R}^{2}=$ 0,875 menunjukkan bahwa kontribusi atau sumbangan pengaruh pemberdayaan karyawan (X) terhadap kepercayaan pada pengawas (M) sebesar 87,50 persen, sedangkan sisanya 12,5 persen dipengaruhi oleh faktor lainnya yang tidak dimasukkan dalam model tersebut.Dari angka tersebutdapat dijelaskan bahwa variabel pemberdayaan karyawan $(\mathrm{X})$ berpengaruh nyata terhadap kepercayaan pada pengawas (M). Hal ini dibuktikan dari t hitung sebesar 22,447, sedangkan $\mathrm{t}$ tabel 12,706 pada derajat bebas $\left(\mathrm{df}_{1}=1\right) 1$ ebih kecil dari angka tersebut.

Hal ini dibuktikan dari thitung sebesar 22,447, sedangkan t tabel 1,993 pada derajat bebas $\left(\mathrm{df}_{2}=72\right)$ lebih kecil dariangka tersebut.Pengaruh variabel pemberdayaan karyawan (X) terhadap kepercayaan pada pengawas (M) dapat dilihat pada nilai signifikansi sebesar 0,000 dengan probabilitas lebih kecil dari 1 persen. 
Laporan hasil analisis jalur persamaanregresi model II setelah diolah dapat dibentuk persamaan substruktur 1 sebagai berikut.

Persamaan substruktur 2:

$$
\begin{array}{rl}
\mathbf{Y} & \mathbf{r} \mathbf{c X}+\mathbf{b M}+\mathbf{e} 2 \ldots \ldots \ldots \ldots \ldots \ldots \ldots \ldots \ldots \ldots \ldots \ldots \ldots \ldots \\
\mathrm{Y} & =0,431 \mathrm{X}+0,411 \mathrm{M} \\
\mathrm{S}(ß) & =(0,431) \quad(0,411) \\
\mathrm{t} & =(2,293) \quad(2,188) \\
\mathrm{Sig} & =(0,025) \quad(0,032) \\
\mathrm{R}^{2} & =(0,686) \quad \text { df } 1=1 \quad \mathrm{df}_{2}=71 \mathrm{~F}=77,682 \quad \mathrm{Sig}=0,000
\end{array}
$$

Hasil perhitungan $\mathrm{F}$ sebesar 77,682 dengan nilai signifikansi sebesar 0,000, yang berarti lebih kecil dari alpha 0,05 . Hasil ini memberikan kesimpulan bahwa regresi model II yaitu variabel pemberdayaan karyawan(X) dan kepercayaan pada pengawas (M) berpengaruh serempak pada variabel perilaku kerja inovatif (Y). Besarnya nilai $\mathrm{R}^{2}=0,686$ menunjukkan bahwa kontribusi atau sumbangan pengaruh pemberdayaan karyawan $(\mathrm{X})$ dan kepercayaan pada pengawas $(\mathrm{M})$ terhadap perilaku kerja inovatif sebesar 68,60 persen, sedangkan sisanya 31,40 persen dipengaruhi oleh faktor lainnya yang tidak dimasukkan dalam model tersebut.

Dari angka tersebut dapat dijelaskan bahwa variabel pemberdayaan karyawan (X) dan kepercayaan pada pengawas (M) berpengaruh tidak nyata terhadap perilaku kerja inovatif (Y). Dapat dinyatakan dari t hitung sebesar 2,393 dan 2,188, sedangkan $\mathrm{t}$ tabel 4,303 pada derajat bebas $\left(\mathrm{df}_{1}=2\right)$ lebih besar dari angka tersebut. 
Selanjutnya, variabel pemberdayaan karyawan (X) dan kepercayaan pada pengawas (M) berpengaruh nyata terhadap perilaku kerja inovatif (Y). Hal ini dibuktikan dari t hitung masing-masing sebesar 2,393 dan 2,188, sedangkan $\mathrm{t}$ tabel 1,994pada derajat bebas $\left(\mathrm{df}_{2}=71\right)$ lebih kecil dari angka tersebut.

Pengaruh variabel pemberdayaan karyawan $(\mathrm{X})$ dan kepercayaan pada pengawas (M) terhadap perilaku kerja inovatif (Y) dapat dilihat pada nilai signifikansi kedua variabel masing-masing sebesar 0,025 dan 0,032 atau dengan probabilitas lebih kecil dari 1 persen.

1. Menguji nilai variabel error (e)

Berdasarkan model I dan II, maka terbentuklah model diagram jalur akhir yang terlebih dahulu dihitung nilai standar error sebagai berikut:

$$
\begin{aligned}
& \mathrm{e}=\sqrt{1-\mathrm{R}_{\mathrm{i}}{ }^{2}} \ldots \ldots \ldots \ldots \ldots \ldots \ldots \ldots \ldots \ldots \ldots \ldots \\
& \mathrm{e}_{1}=\sqrt{1-R^{2}}=\sqrt{1-0,875}=0,353 \\
& \mathrm{e}_{2}=\sqrt{1-R^{2}}=\sqrt{1-0,686}=0,560
\end{aligned}
$$

Hasil pengaruh error $\left(e_{1}\right)$ 0,353 dan pengaruh error $\left(e_{2}\right)$ 0,560, dengan hasil koefisien determinasi total sebagai berikut:

$$
\begin{aligned}
\mathrm{R}^{2} \mathrm{~m} & =1-\left(\mathrm{e}_{1}\right)^{2}\left(\mathrm{e}_{2}\right)^{2} \ldots \ldots \ldots . \\
& =1-(0,353)^{2}(0,560)^{2} \\
& =0,9839
\end{aligned}
$$

Nilai determinasi total 0.9839 mempunyai arti bahwa 98,39\% perilaku kerja inovatif dipengaruhi oleh pemberdayaan karyawan dan kepercayaan pada pengawas, sedangkan sisanya sebesar 1,61\% dipengaruhi oleh faktor lain yang tidak ada dalam model. 
2. Menghitung koefisien jalur yang didasarkan koefisien regresi.

1) Pengaruh langsung

(1) Pengaruh variabel pemberdayaan karyawan (X) terhadap kepercayaan pada pengawas (M)

$\mathrm{X} \rightarrow \mathrm{M}=0,935$

(2) Pengaruh variabel pemberdayaan karyawan $(\mathrm{X})$ terhadap perilaku kerja inovatif (Y)

$X \rightarrow Y=0,431$

(3) Pengaruh variabel terhadap kepercayaan pada pengawas (M) terhadap perilaku kerja inovatif (Y)

$$
\mathrm{M} \rightarrow \mathrm{Y}=0,411
$$

2) Pengaruh tidak langsung

Pengaruh variabel pemberdayan karyawan (X) terhadap perilaku kerja inovatif (Y) dengan kepercayaan pada pengawas (M) sebagai perantara

$$
X \rightarrow M \rightarrow Y=\left(\rho_{1}\right) \times\left(\rho_{3}\right)=(0,935 \times 0,411)=0,384
$$

3) Pengaruh total

Total pengaruh variabel $\mathrm{X}$ terhadap $\mathrm{Y}$ melalui $\mathrm{M}$ dirumuskan sebagai berikut:

$$
\begin{aligned}
\text { Pengaruh total } & =c+(a \times b) \\
& =0,431+(0,935 \times 0,411) \\
& =0,815
\end{aligned}
$$


Tabel 16.

Persamaan Regresi Model I

Pengaruh Pemberdayaan Karyawan terhadap Kepercayaan pada Pengawas

\begin{tabular}{|c|c|c|c|c|c|}
\hline \multirow{2}{*}{ Variabel } & \multicolumn{2}{|c|}{ Unstandarized } & \multirow{2}{*}{$\begin{array}{c}\text { Standarized } \\
\text { Coeficients } \\
\text { Beta } \\
\end{array}$} & \multirow[t]{2}{*}{$\mathbf{t}$} & \multirow[t]{2}{*}{ Sig. } \\
\hline & B & Std Error & & & \\
\hline (Constant) & 0,955 & 0,857 & & 1,115 & 0,269 \\
\hline $\begin{array}{l}\text { Pemberdayaan } \\
\text { Karyawan (X) }\end{array}$ & 1,193 & 0,053 & 0,935 & 22,447 & 0,000 \\
\hline $\mathbf{R}^{2}$ & \multicolumn{2}{|c|}{0,875} & & & \\
\hline F Hitung & \multicolumn{2}{|c|}{503,874} & & & \\
\hline Sig. F & \multicolumn{2}{|c|}{0,000} & & & \\
\hline
\end{tabular}

Tabel 16 menyatakan persamaan regresi model I yang memiliki persamaan struktural sebagai berikut:

$$
\begin{aligned}
& M=a X+e_{1} \\
& M=0,935 X
\end{aligned}
$$

Nilai F hitung pada tabel 16 berjumlah 503.874 dengan signifikansi 0,000. Nilai signifikansi <alpha 0,05 yang menunjukkan, pemberdayaan karyawandapat digunakan untuk menilai kepercayaan pada pengawas, atau dengan kata lain pemberdayaan karyawan(X) berpengaruh positif dan signifikan terhadap kepercayaan pada pengawas (M).

Tabel 17.

Persamaan Regresi Model II

Pengaruh Pemberdayaan Karyawan terhadapPerilaku Kerja Inovatif

\begin{tabular}{|c|c|c|c|c|c|}
\hline \multirow[t]{2}{*}{ Variabel } & \multicolumn{2}{|c|}{ Unstandarized } & \multirow{2}{*}{$\begin{array}{c}\text { Standarized } \\
\text { Coeficients } \\
\text { Beta } \\
\end{array}$} & \multirow[t]{2}{*}{$\mathbf{T}$} & \multirow{2}{*}{ Sig. } \\
\hline & B & Std Error & & & \\
\hline (Constant) & 3,813 & 0,991 & & 3,846 & 0,000 \\
\hline $\begin{array}{l}\text { Pemberdayaan } \\
\text { karyawan (X) }\end{array}$ & 0,395 & 0,172 & 0,431 & 2,293 & 0,025 \\
\hline $\begin{array}{l}\text { Kepercayaan pada } \\
\text { Pengawas(M) }\end{array}$ & 0,296 & 0,135 & 0,411 & 2,188 & 0,032 \\
\hline $\mathbf{R}^{2}$ & \multicolumn{2}{|c|}{0,686} & & & \\
\hline F Hitung & \multicolumn{2}{|c|}{77,682} & & & \\
\hline Sig. F & \multicolumn{2}{|c|}{0,000} & & & \\
\hline
\end{tabular}
Melalui Variabel Kepercayaan pada Pengawas

Sumber: data diolah, 2018 
Tabel 17 menyatakan persamaan regresi model II yang memiliki persamaan struktural sebagai berikut :

$$
\begin{aligned}
& Y=c X+b M+e_{2} \\
& Y=0,431 X+0,411 M
\end{aligned}
$$

Tabel 17 menyatakan nilai $F$ hitung 77,682 dengan signifikansi 0,000. Nilai signifikansi tersebut <alpha 0,05 yang menyatakan bahwa pemberdayaan karyawan (X) dan kepercayaan pada pengawas(M) dapat digunakan untuk memprediksi perilaku kerja inovatif (Y), atau dapat dikatakan bahwa pemberdayaan karyawan (X)dan kepercayaan pada pengawas(M) secara serempak berpengaruh positif dan signifikan terhadap perilaku kerja inovatif (Y).

Berdasarkan model I dan II, disusunlah model diagram jalur akhir. Sebelumdisusun model diagram jalur akhir, terlebih dahulu dihitung nilai standar error sebagai berikut:

$$
\begin{aligned}
& \mathrm{e}=\sqrt{1-\mathrm{R}_{\mathrm{i}}{ }^{2}} \\
& \mathrm{e}_{1}=\sqrt{1-R^{2}}=\sqrt{1-0,875}=0,353 \\
& \mathrm{e}_{2}=\sqrt{1-R^{2}}=\sqrt{1-0,686}=0,560
\end{aligned}
$$

Hasil pengaruh error $\left(e_{1}\right)$ 0,353 dan pengaruh error $\left(e_{2}\right)$ 0,560. Hasil koefisien determinasi total sebagai berikut:

$$
\begin{aligned}
\mathrm{R}^{2} \mathrm{~m} & =1-\left(\mathrm{e}_{1}\right)^{2}\left(\mathrm{e}_{2}\right)^{2} \\
& =1-(0,353)^{2}(0,560)^{2} \\
& =0,9839
\end{aligned}
$$


3. Menghitung koefisien jalur yang didasarkan koefisien regresi.

4) Pengaruh langsung

(1) Pengaruh variabel pemberdayaan karyawan (X) terhadap kepercayaan pada pengawas (M)

$\mathrm{X} \rightarrow \mathrm{M}=0,935$

(2) Pengaruh variabel pemberdayaan karyawan $(\mathrm{X})$ terhadap perilaku kerja inovatif (Y)

$\mathrm{X} \rightarrow \mathrm{Y}=0,431$

(3) Pengaruh variabel terhadap kepercayaan pada pengawas (M) terhadap perilaku kerja inovatif (Y)

$\mathrm{M} \rightarrow \mathrm{Y}=0,411$

5) Pengaruh tidak langsung

Pengaruh variabel pemberdayan karyawan (X) terhadap perilaku kerja inovatif (Y) dengan kepercayaan pada pengawas (M) sebagai perantara

$$
X \rightarrow M \rightarrow Y=\left(\rho_{1}\right) \times\left(\rho_{3}\right)=(0,935 \times 0,411)=0,384
$$

6) Pengaruh total

Total pengaruh variabel $\mathrm{X}$ terhadap $\mathrm{Y}$ melalui $\mathrm{M}$ dirumuskan sebagai berikut:

$$
\begin{aligned}
\text { Pengaruh total } & =c+(a \times b) \\
& =0,431+(0,935 \times 0,411) \\
& =0,815
\end{aligned}
$$


Tabel 18.

Pengaruh Langsung, Pengaruh Tidak Langsung serta Pengaruh Total Pemberdayaan Karyawan (X), Kepercayaan pada Pengawas (M) dan Perilaku Kerja Inovatif $(\mathbf{Y})$

\begin{tabular}{lccc}
\hline \multicolumn{1}{c}{$\begin{array}{c}\text { Pengaruh } \\
\text { Variabel }\end{array}$} & $\begin{array}{c}\text { Pengaruh } \\
\text { Langsung }\end{array}$ & $\begin{array}{c}\text { Pengaruh Tidak Langsung } \\
\text { Melalui M } \\
(\mathbf{a} \text { x b })\end{array}$ & Pengaruh Total \\
\hline $\mathrm{X} \rightarrow \mathrm{Y}$ & 0,935 & - & 0,935 \\
$\mathrm{X} \rightarrow \mathrm{M} \rightarrow \mathrm{Y}$ & 0,431 & 0,384 & 0,815 \\
$\mathrm{M} \rightarrow \mathrm{Y}$ & 0,411 & - & 0,411 \\
\hline
\end{tabular}

Sumber:Data Primer Diolah, 2018

Berdasarkan persamaan struktur diatas, dinyatakan bahwa diagram koefisien jalur dari penelitian ini adalah sebagai berikut:

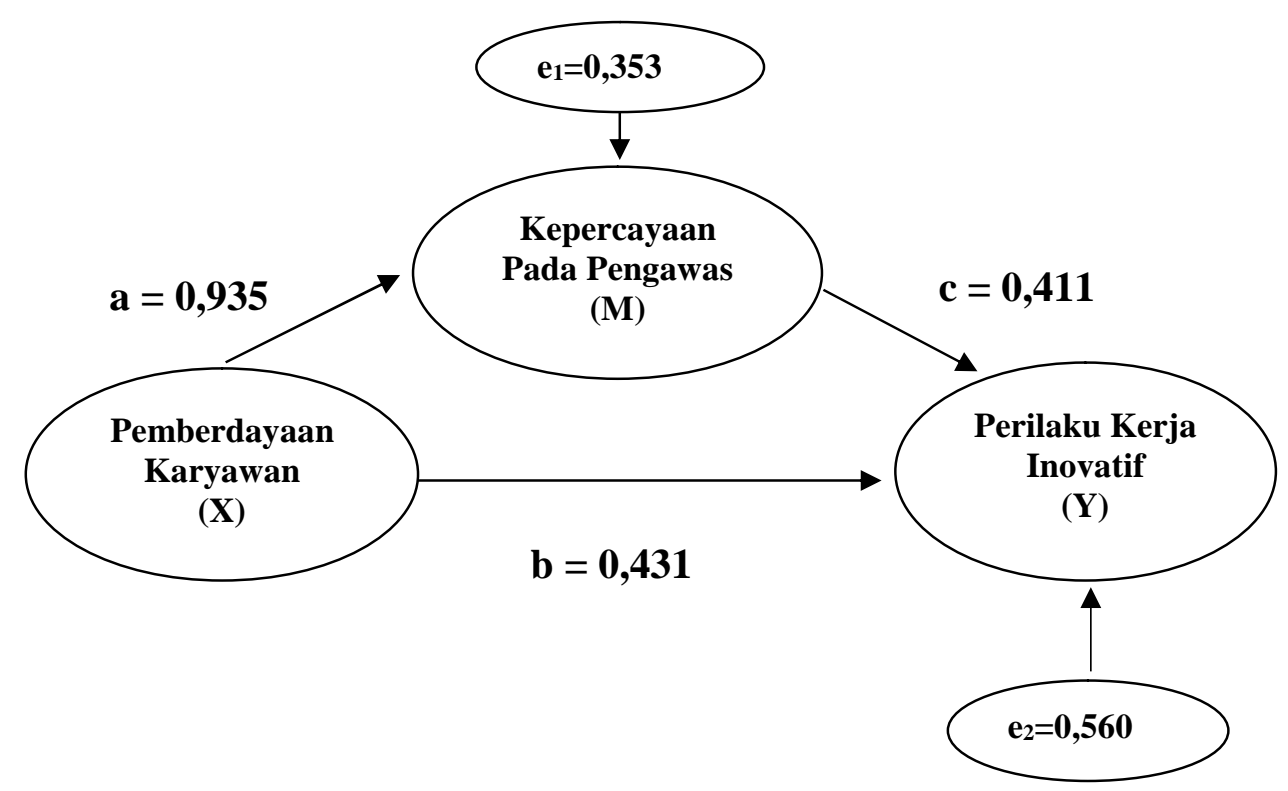

Gambar 2. Validasi Model Diagram Jalur Akhir Sumber: Data Primer Diolah, 2018

Berdasarkan gambar 2, dapat diketahui bahwa pengaruh langsung pemberdayaan karyawanterhadap kepercayaan pada pengawasadalah sebesar 0,935. Pengaruh langsung kepercayaan pada pengawasterhadap perilaku kerja 
inovatifadalah sebesar 0,411. Pengaruh langsung pemberdayaan karyawan terhadap perilaku kerja inovatif adalah sebesar 0,431. Pengaruh tidak langsung pemberdayaan karyawan terhadap perilaku kerja inovatif adalah melalui kepercayaan pada pengawasadalah sebesar 0,384 .

\section{Hasil Analisis Sobel}

Menguji signifikansi pengaruh tidak langsung dapatmelalui nilai z dari koefisien ab dengan rumus sebagai berikut:

$$
z=\frac{a b}{S_{a b}}
$$

Keterangan:

$$
\begin{aligned}
& \mathrm{S}_{\mathrm{ab}}=\text { besarnya standar error tidak langsung } \\
& \mathrm{ab}=\text { jalur (a) dikali jalur }(\mathrm{b}) \\
& z=\frac{(0,935)(0,411)}{0,12829} \\
& z=2,9954
\end{aligned}
$$

Kriteria pengujian:

$\mathrm{H}_{0}$ diterima dan $\mathrm{H}_{1}$ ditolak apabila $\mathrm{z}$ hitung $\leq \mathrm{z}$ tabel $=1,96$

$\mathrm{H}_{0}$ ditolak dan $\mathrm{H}_{1}$ diterima apabila $\mathrm{z}$ hitung $>\mathrm{z}$ tabel $=1,96$

Tabel 19.

Hasil Uji Sobel

\begin{tabular}{cc}
\hline Nilai Z & Sig \\
\hline 2,9954 & 0,000 \\
\hline
\end{tabular}

Sumber: data diolah, 2018 
Perbandingan nilai z hitung 2,9954 > z tabel 1,96 maka $\mathrm{H}_{0}$ ditolak dan $\mathrm{H}_{1}$ diterima. Artinya kepercayaan pada pengawas berpengaruh signifikan dan positif dalam memediasi pemberdayaan karyawan terhadap perilaku kerja inovatif karyawan pada Bale Udang Mang Engking Ubud.

\section{Pembahasan Hasil Penelitian}

\section{Pengaruh Pemberdayaan Karyawan terhadap Kepercayaan pada Pengawas}

Berdasarkan perhitungan yang diperoleh bahwa hasil perhitungan menunjukan standardized beta sebesar 0,935 dengan tingkat signifikansi sebesar $0,000<0,05$. Dari perolehan angka tersebut muncul indikasi dan dapat memberikan gambaran bahwa pemberdayaan karyawan memiliki pengaruh yang positif dan signifikan terhadap kepercayaan pada pengawas.

Hasil uji dari penelitian ini sejalan dengan penelitian yang dilakukan oleh Moye \& Henkin (2006) yang menyatakan bahwa, karyawan yang diberdayakan pada lingkungan kerjanya akan memiliki kepercayaan tinggi pada atasan atau pengawas mereka di Perusahaan Manufaktur Amerika Serikat. Karyawan yang diberdayakan oleh atasan atau pengawas akan merasa diberi kepercayaan lebih oleh atasan atau pengawasnya sehingga karyawan tersebut akan memiliki kepercayaan yang sama juga kepada atasan atau pengawasnya. Dengan demikian dapat disimpulkan bahwa pemberdayaan karyawan berpengaruh positif signifikan terhadap kepercayaan pengawas.

\section{Pengaruh Pemberdayaan Karyawan terhadap Perilaku Kerja Inovatif}

Hasil perhitungan yang diperoleh menunjukkan bahwa nilai standardized beta sebesar 0,431 dengan tingkat signifikansi sebesar 0,025 $<0,05$. Hal ini 
mengindikasikan bahwa variabel pemberdayaan karyawan berpengaruh secara positif dan signifikan terhadap perilaku kerja inovatif karyawan Bale Udang Mang Engking Ubud.

Hasil penelitian ini telah sejalan dengan penelitian Alkhodary (2016) yang mengemukakan bahwa dengan adanya pemberdayaan karyawan maka tercipta perilaku kerja inovatif pada karyawan dalam sebuah perusahaan desain interior di Yordania. Pemberdayaan karyawan mampu menciptakan suatu ide, proses, maupun prosedur baru yang mampu menunjang kinerja karyawan secara efektif dan efisien. Dengan demikian dapat disimpulkan bahwa pemberdayaan karyawan berpengaruh positif signifikan terhadap perilaku kerja inovatif.

\section{Pengaruh Kepercayaan pada Pengawas terhadap Perilaku Kerja Inovatif}

Hasil perhitungan yang diperoleh menunjukkan bahwa nilai standardized beta sebesar 0,431 dengan tingkat signifikansi sebesar $0,032<0,05$. Hal ini mengindikasikan bahwa kepercayaan pada pengawas berpengaruh secara positif dan signifikan terhadap perilaku kerja inovatif karyawan Bale Udang Mang Engking Ubud.

Hasil penelitian ini berbanding lurus dengan penelitian sebelumnya olehNehles (2016) yang mengemukakan bahwa adanya kepercayaan pada pengawas yang tinggi dapat mempengaruhi perilaku kerja inovatif karyawanpemadam kebakaran di Belanda. Kepercayaan pada pengawas mampu memberi ruang bagi para karyawan untuk mengemukakan segala pemikiran yang kreatif dan inovatif dalam penunjang kinerja di perusahaan. Dengan demikian 
dapat disimpulkan bahwa kepercayaan pada pengawas berpengaruh positif terhadap perilaku kerja inovatif.

\section{Peran Kepercayaan pada Pengawas Mediasi Pemberdayaan Karyawan terhadap Perilaku Kerja Inovatif}

Hasil penelitian pada pengujian pemberdayaan karyawan terhadap kepercayaan pada pengawas, diperoleh nilai standardized beta0,935 dan signifikannya $0,000<0,05$ yang menyatakan pemberdayaan karyawan berpengaruh positif signifikan terhadap kepercayaan pada pengawas. Nilai standardized beta 0,935 merupakan nilai jalur a.

Pada persamaan regresi model II, nilai standardized beta untuk pemberdayaan karyawan yaitu 0,431 memberikan pengaruh yang signifikan. Nilai standardized beta kepercayaan pada pengawas yaitu 0,411 memberikan pengaruh yang positif signifikan. Nilai standardized beta pemberdayaan karyawan yaitu 0,431 merupakan nilai jalur c dan nilai standardized beta kepercayaan pada pengawas yaitu 0,411 merupakan nilai jalur b. Berdasarkan perhitungan nilai variabel error (e) diketahui nilai $\mathrm{e}_{1}=0,353$ dan $\mathrm{e}_{2}=0,560$.

Dapat disimpulkan bahwa hasil analisis jalur menyatakan pemberdayaan karyawan memberi pengaruh secara langsung dan tidak langsung terhadap perilaku kerja inovatif dengan kepercayaan pada pengawas .Berdasarkan hasil yang diperoleh, hipotesis pengaruh tidak langsung antara pemberdayan karyawan terhadap perilaku kerja inovatif melalui variabel kepercayaan pada pengawas dapat diterima. 


\section{SIMPULAN DAN SARAN}

Pemberdayaan karyawan berpengaruh positif dan signifikan terhadap kepercayaan pada pengawas di Bale Udang Mang Engking Ubud. Semakin tinggi pemberdayaan karyawan yang dikembangkan maka akan menciptakan kepercayaan pada pengawasyang meningkat pada karyawan.Pemberdayaan karyawan berpengaruh positif dan signifikan terhadap perilaku kerja inovatif di Bale Udang Mang Engking Ubud. Semakin tinggi pemberdayaan karyawan yang dikembangkan maka akan menciptakan perilaku kerja inovatifyang meningkat pada karyawan.Kepercayaan pada pengawas berpengaruh positif dan signifikan terhadap perilaku kerja inovatif di Bale Udang Mang Engking Ubud. Semakin tinggi kepercayaan pada pengawas yang diperoleh maka akan menciptakan perilaku kerja inovatifkaryawan yang meningkat di Bale Udang Mang Engking Ubud.

Kepercayaan pada pengawas memiliki peran memediasi pengaruh pemberdayaan karyawan terhadap perilaku kerja inovatif pada karyawan di Bale Udang Mang Engking Ubud.Secara tidak langsung pemberdayaan karyawan memiliki pengaruh yang positif dan signifikan melalui kepercayaan pada pengawas terhadap perilaku kerja inovatif karyawan di Bale Udang Mang Engking Ubud. Secara langsung pemberdayaan karyawan juga berpengaruh terhadap perilaku kerja inovatif karyawan di Bale Udang Mang Engking Ubud. Artiya bahwa secara langsung maupun tidak langsung pemberdayaan karyawan berpengaruh positif signifikan terhadap perilaku kerja inovatif karyawan di Bale Udang Mang Engking Ubud. 
Adapun saran-saran yang dapat diberikan meliputi Pemberdayaan karyawan perlu didukung dengan pelatihan keahlian dan penambahan wawasan yang sesuai bidang karyawan tersebut karena akan menjadi modal penting bagi karyawan meningkatkan perilaku kerja inovatif di Bale Udang Mang Engking Ubud.Kepercayaan pada pengawas perlu ditingkatkan lagi dari sisi kepekaan dan kepedulian sosial yang mampu memberi dorongan serta semangat bagi karyawan dalam mengambil sikap dan berani untuk mengembangkan perilaku kerja inovatif.

\section{REFERENSI}

Alkhodary, Dina. 2016. The Relationship between Employees' Empowerment and Innovative Work Behavior. International Journal of Managerial Studies and Research. Vol. 04, No. 02. pp. 1-15.

Berraies, Sarra. 2014 Employee Empowerment and Its Importance for Trust,Innovation and Organizational Performance. Business Management and Strategy Journal. Vol.05, No.02, pp. 82-103.

Brunetto, Yvonne, and Farr-Wharton, Rod. 2007. The Moderating Role of Trust in SME Owner/Managers' Decision-Making about Collaboration. Journal of Small Business Management.Vol.45. No. 03.pp. 362-387

Byaruhanga, Ismael. and Othuma, Patrick B. 2014. Employee empowerment, trust, engagement, and organizational citizenship behavior (OCB). $9^{\text {th }}$ International Academic Conference. Instanbul, April $13^{\text {th }} 2014$.

Çakar, N. D., and Ertürk, A. 2010. Comparing innovation capability of small and medium-sized enterprises, examining the effects of organizational and empowerment. Journal of Small Business Management. Vol. 48.No.03. pp. 325-559.

De Jong, J., and Hartog,Den.D. 2010. Measuring Innovative Work Behaviour. Creativity and Innovation Management, Vo.1. No.1, pp.23-36.

Ertürk, Alper. 2012. Linking Psychological Empowerment to Innovation Capability:Investigating the moderating Effect of Supervisory Trust. International Journal of Businessand Social Science. Vol.3, No. 14,pp. 153-165. 
Ghozali, Imam. 2006. Aplikasi Analisis Multivariate dengan Program SPSS. Edisi Keempat. Semarang: Badan Penerbit Universitas Diponegoro.

Khodabakhshi, F., Sajad, N. K., and Shiargar, M. 2013. The Impact of Knowledge management on Innovation with the mediating role of empowerment. Life Science Journal. Vol. 10, No.02, pp. 1385-1390.

Lee, Seow Hwan., 2008.The Effect of Employee Trust and Commitment on Innovative Behavior in the Public Sector: An Empirical Study. International Review of public administration Journal. Vol.3, No.01, pp.27-46.

Moye, Melinda J., and Henkin, Alan B.. 2006. Exploring associations between employee empowerment and interpersonal trust in managers.Journal of Management Development, Vol. 25 Issue: 2, pp.101-117.

Nehles, Anna.Boss., 2016. Innovative work behaviour in knowledge-intensive public sector organizations: the case of supervisors in the Netherlands fire services. The International Journal of Human Resource Management.Vol.28, No.02, pp. 379-398.

Ratnawati.dan Amri, Khairul. 2013. Pengaruh keadilan organisasional, kepercayaan pada atasan terhadap perilaku kewargaan organisasi (Organizational Citizenship Behavior). Jurnal Ekonomi Manajemen dan Bisnis. Vol.1,No.1.hal. 56-73.

Saswitaningrum, Ch, Ndaru.T., 2013. Pengaruh Self Effcacy dan Kepercayaan (Trust to ward leader) terhadap perilaku kerja inovatif guru (Innovative work behaviour) di SMK 2 Sewon Bantul.Tesis Fakultas Ekonomi dan Bisnis Universitas Gajah Mada.

Seo, Hyo Min., Kim, Min, Cheol., Chang, Kyungro, Kim Taehee.2016. Influence of Interpersonal Trust on Innovative Behaviour of Service Workers: Mediating effect of Knowledge Sharing. International Journal of Innovation Management.Vol.20, No.02, pp. 1-21.

Shelton, Samuel T. 2002. Employees, Supervisors, and Empowerment in the Public Sector: The Role of Employee Trust. Dissertation Public Administration.

Sugiyono. 2014. Metode Penelitian Bisnis. Cetakan Kesebelas. Bandung: C.V Alfabeta.

Suryadewi,Putu.Chori., Dunia, I Ketut., Suharsono,Naswan.2014. Pengaruh Pemberdayaan Karyawan Terhadap Kinerja Karyawan pada PT. Bali 
Ni Nyoman Surya Cahyani, Peran Kepercayaan pada Pengawas...

Segara Nusantara. Jurnal Fakultas Pendidikan Ekonomi Universitas Pendidikan Ganesha, Vol.4, No.1.

Wibowo. 2012. Manajemen Kinerja. Edisi ketiga. Jakarta:PT. Raja Grafindo Persada. 